\title{
MPPT control design for variable speed wind turbine
}

\author{
Meriem Otmane Rachedi, Mohammed Larbi Saidi, Fayçel Arbaoui \\ Laboratory of Automatic and Signals, Annaba (LASA), Department of Electronics, Badji Mokhtar University, Algeria
}

\begin{tabular}{|c|c|}
\hline Article Info & ABSTRACT \\
\hline & \multirow{10}{*}{$\begin{array}{l}\text { Variable speed wind turbine systems (VSWT's) have been in receipt of } \\
\text { extensive attention among the various renewable energy systems. } \\
\text { The present paper focuses on fuzzy fractional order proportional-integral } \\
\text { (FFOPI) control segment for variable speed wind turbine (VSWT) directly } \\
\text { driving permanent magnet synchronous generator (PMSG). The main } \\
\text { objective of this study is to reach maximum power point tracking (MPPT) } \\
\text { through combination of advanced control based on FFOPI control applied to } \\
\text { generator side converter (turbine and PMSG). The basic idea of the FFOPI } \\
\text { controller is to implement a fuzzy logic controller (FLC) in cascade with } \\
\text { Fractional Order Proportional Integral controller (FOPI). A comparative } \\
\text { study with FOPI and classical PI control schemes is made. The traditional PI } \\
\text { controller cannot deliver a sufficiently great performance for the VSWT. } \\
\text { However, the results found that the proposed approach (FFOPI) is more } \\
\text { effective and feasible for controlling the permanent magnet synchronous } \\
\text { generator to mantain maximum power extraction. The validation of results } \\
\text { has been performed through simulation using Matlab/Simulink®. }\end{array}$} \\
\hline Received Oct 20, 2019 & \\
\hline Revised Mar 28, 2020 & \\
\hline Accepted Apr 8, 2020 & \\
\hline Keywords: & \\
\hline $\begin{array}{l}\text { Fractional order proportional- } \\
\text { integral }\end{array}$ & \\
\hline Fuzzy logic controller & \\
\hline MPPT & \\
\hline PMSG & \\
\hline Wind turbine & \\
\hline
\end{tabular}

Copyright $\left({ }_{0}\right.$ 2020Institute of Advanced Engineering and Science. All rights reserved.

\section{Corresponding Author:}

Meriem Otmane Rachedi,

Department of Electronics Engineering,

Laboratory of Automatic and Signals, Annaba (LASA),

Badji Mokhtar University,

P.O. Box 12, Annaba 23000, Algeria.

Email: meriem.othmanerachedi@univ-annaba.org

\section{INTRODUCTION}

An alternative energy source such as wind energy is more environmentally acceptable when compared to the traditional fossil fuels-based energy sources. Wind power depends mainly on geographic and climate conditions. For that reason, it is required to build a system able to generating maximum power beneath these constraints [1].

From the wind speed, wind turbine systemsproducts the electrical energy after converting wind speed to mechanical energy by the generator. Several wind turbines use the doubly fed induction generator (DFIG) using wound-rotor or cage type rotor [2]. The connection of the wind turbine to the generator with the gearbox causes the problems related with variable-speed wind systems. Nowadays, PMSG's are favored due to their, high-power density, lightweight, and high efficiency. Such machines are often directly connected to the turbine removing the need of a gearbox. This reduces the overall cost and reliability of the system [3]. The schematic block diagram of the overall system is presented in Figure 1.

The power output from wind turbines varies nonlinearly with enormous and sudden variations in wind speed, therefore the use of an MPPT controller is indispensable to optimize the generator speed and power output measurements in order to maximize the output power whatever wind speed. The control algorithm allows reaching and tracking the maximum power point MPP at all wind velocities. Over the years, several control methods have been proposed for extracting maximum power from wind to overcome various constraints such as Optimal Tip Speed Ratio Control $[4,5]$ has developed nonlinear proportional complex integral (PCI), fuzzy controller [6,7], artificial neural networks (ANN) [8], robust control [9], DTC based 
sliding mode control [10], direct adaptive fuzzy-PI controller and using ANN-PSO wind speed estimator [11], robust adaptive neural controller $[12,13]$ has proposed Experimental enhancement of fuzzy fractional order PI+I controller of grid connected variable speed wind energy conversion system.

This study presents a FFOPI controlled MPPT system suitable for the permanent magnet synchronous generator operating at variable speeds. The MPPT systemmethod uses FLC to creäte the reference speed that maximizes the extracted power from the turbine. In the same part the fractional order PI algorithm is used to attain the speed control of the generator for each wind speed extracting maximum power output of turbine.

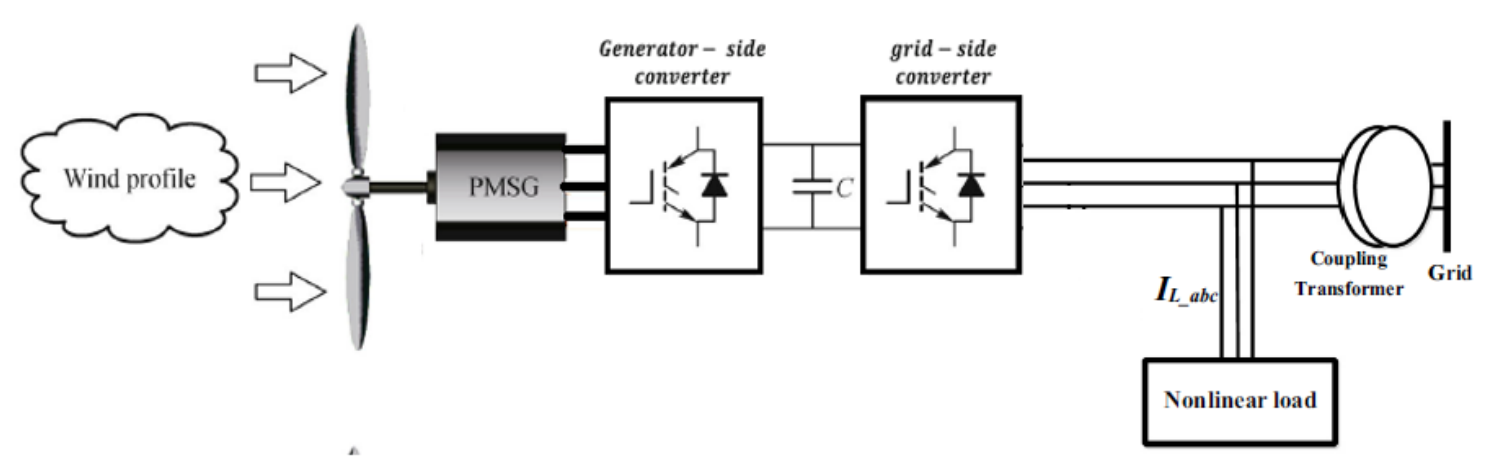

Figure 1. The schematic block diagram of variable-speed wind turbine

The remainder of this paper is ordered as follows: In Section 2, the system modeling is described. Section 3 presents in detail the proposed control strategy. Section 4 is devoted to present the simulations results. Finally, the paper is concluded in Section 5.

\section{SYSTEM MODELING}

\subsection{Wind model}

The wind speed is modeled by a sum of numerous harmonics as follows [14]:

$$
v(t)=A+\sum_{n=1}^{i} a_{n} \sin \left(b_{n} . w_{v} . t\right)
$$

\subsection{Turbine's model}

The turbine rotor reduces the air speed and at the same time transforms the absorbed kinetic energy of the air into mechanical power. The mechanical power of the wind turbine is given by [15]:

$$
P_{t}=\frac{1}{2} \rho \pi R^{2} v_{\text {wind }}^{3} C_{p}(\lambda, \beta)
$$

where, $P_{t}$ is the captured wind power $(\mathrm{W}), \rho$ is the air density $(\mathrm{kg} / \mathrm{m} 3), R$ is the radius of rotor blade $(\mathrm{m})$, $v_{\text {wind }}$ is wind speed $(\mathrm{m} / \mathrm{s})$, and $C_{p}$ is the power coefficient. $\lambda$ is defined as:

$$
\lambda=\frac{\Omega_{t} R}{v_{\text {wind }}}
$$

where: $\Omega_{t}$ is the turbine rotational speed. The value of power coefficient $C_{p}$ is depends on tip speed ratio $(\lambda)$ and blade pitch angle $(\beta)$ based on the turbine characteristics governed by [16]:

$$
C_{p}(\lambda, \beta)=C_{1}\left(\frac{C_{2}}{\lambda_{i}}-C_{3} \beta-C_{4}\right) e^{\frac{C_{5}}{\lambda_{i}}}+C_{6}
$$


with:

$$
\frac{1}{\lambda_{i}}=\frac{1}{\lambda-0.08 \beta}-\frac{0.035}{\beta^{3}+1}
$$

where:

$C_{1}$ to $C_{6}$ signify characteristic coefficients of wind turbine [16]:

So, any variation in the wind speedor the rotor speed induces variation in the tip speed ratio leading to power coefficient change. In this way, the produced power is affected. Figure 2 displays a group of typical $C p$ - $\lambda$ curves.

The maximum value of the power coefficient is given for a null pitch angle and it is equal to: $C_{p \max }=0.48$ Matching to a specific optimal tip speed ratio identical to: $\lambda_{\text {opt }}=8.1$

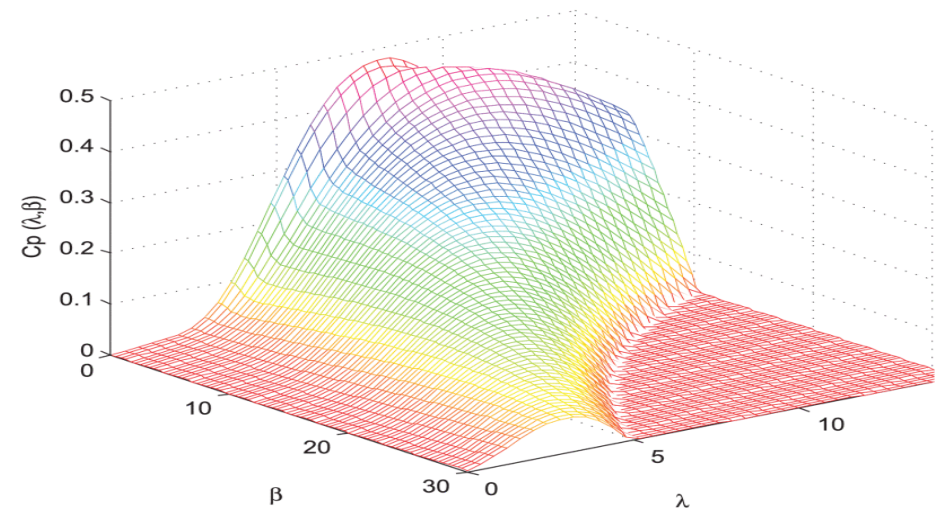

Figure 2. Power coefficient curve

\subsection{Model of PMSG}

To simplify the response study of the generator it is useful to transform the equations from the stationary stator frame into the d-q axis using Park transformations [17]. The simple dynamic model of the PMSG in d, q frame can be denoted by the following equations [18]:

$$
\left\{\begin{array}{l}
v_{s d}=R_{s} I_{s d}+L_{d} \frac{d I_{s d}}{d t}-\omega_{e} L_{q} I_{s q} \\
v_{s q}=R_{s} I_{s q}+L_{q} \frac{d I_{s q}}{d t}-\omega_{e}\left(L_{d} I_{s d}+\psi_{m}\right)
\end{array}\right.
$$

where $V_{s d}, V_{s q}(V)$ are the direct and quadrature mechanisms of the generator voltages, $R s, L d$ and $L q$, one-to-one, are the resistance, the direct and the quadrature inductance of the PMSG winding, $\Psi_{m}(w \mathrm{~b})$ signifies the magnet flux, $\omega_{e}(\mathrm{rad} / \mathrm{s})$ is the electrical rotational speed of PMSG $I_{s d}, I_{s q}(A)$ are the direct and quadrature mechanisms of the generator currents, respectively.

The mechanical dynamic equation of PMSG is governed by [19]:

$$
\frac{d \Omega_{t}}{d t}=\frac{1}{J_{T}} T_{e}+\frac{D_{T}}{J_{T}} \Omega_{t}-\frac{1}{J_{T}} T_{t}
$$

The electromagnetic torque of a p-pole machine is obtained as [19]:

$$
T_{e}=\frac{3}{2} n_{p}\left(\psi_{m} I_{s q}+\left(L_{d}-L_{q}\right) I_{s d} I_{s q}\right.
$$

where $T_{e}(\mathrm{~N} . \mathrm{m})$ is the electromagnetic torque, $n_{p}$ is the number of pole pairs, $D_{T}$ is the damping coefficient, $J_{T}$ is the moment of inertia. 


\section{PROPOSED MPPT CONTROL STRATEGY}

The proposed scheme presents a fuzzy fractional proportional integral controlled maximum power point tracking system appropriate for the permanent magnet synchronous generator at variable speed wind turbine. Several schemes have been proposed to extract MPP from variable-speed wind turbines [20]. Figure 3 shows the proposed algorithm based on the cascade control algorithm FLC with fractional-order PI controller to permanently extract the optimal aerodynamic energy in order to produce the electromagnetic torque reference for each wind speed whereas, the control of the $\mathrm{d}$, q-axis current of the generator, in the interior loop according to the (8) and by field-oriented control strategy (FOC) of the generator to ensure that the system workingsnearby the optimal point, which agrees theextraction of the maximum power by the turbine [21].

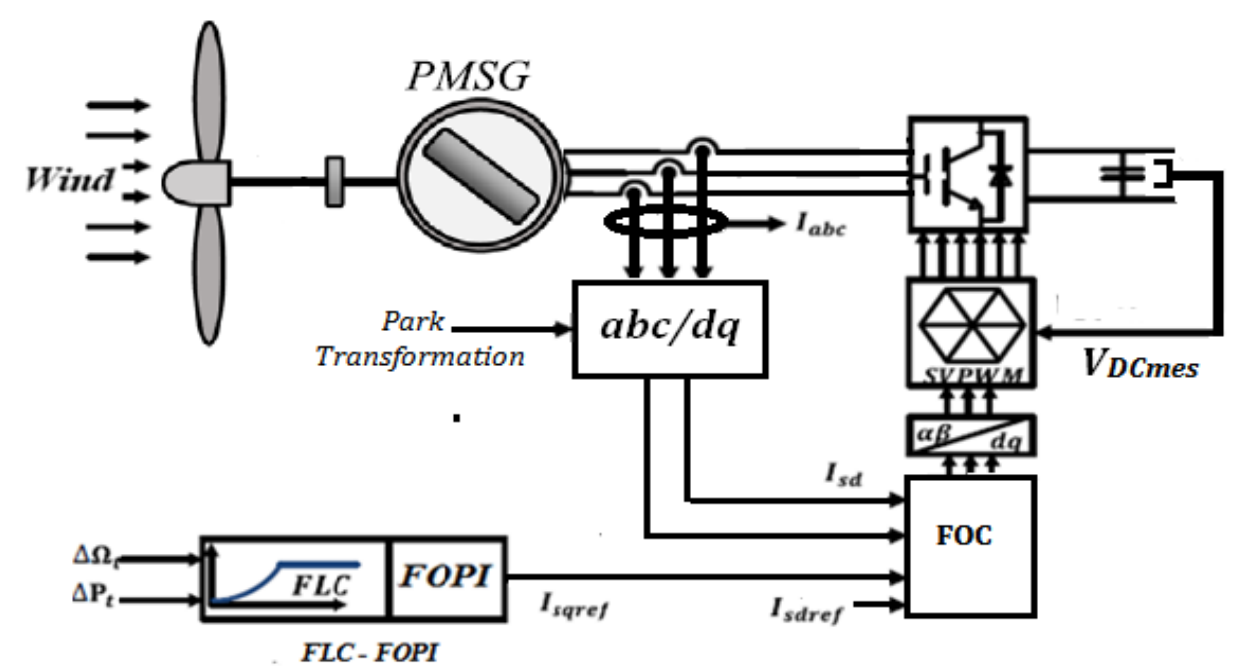

Figure 3. The block diagram of fuzzy fractional order PI controller

In this study it is supposed that pitch angle $\beta$ have a tendency to zero, so that the power output $P_{t}$, differs non-linearly with the turbine angular speed $\left(\Omega_{t}\right)$ and variable wind speeds $\left(v_{\text {wind }}\right)$. Hence, the FLC is used to guarantee a rapid and smooth tracking of the maximum power without the knowledge of the characteristic of the turbine and the wind speed measurement for generating a reference speed $\left(\Omega_{\text {tref }}\right)$ at which the wind turbine should operate, so that maximum power is shaped at the prevalent wind speed. Therefore, a FOPI method is proposed to achieve the speed control of PMSG for each wind speed in the objectif of maximize the extracted power at the turbine output.

The strategy structure of the MPPT method is given in Figure 4. The proposed FLC controller has two inputs $\left(\Delta P_{t}, \Delta \Omega_{t}\right)$ and a single output $\left(\Omega_{\text {tref }}\right)$. They are respectively given by:

$$
\left.\begin{array}{l}
\Delta P_{t}(k)=P_{t}(k)-P_{t}(k-1) \\
\Delta \Omega_{t}(k)=\Omega_{t}(k)-\Omega_{t}(k-1) \\
\Omega_{\text {tref }}(k)=\Delta \Omega_{\text {tref }}(k)+\Omega_{\text {tref }}(k-1)
\end{array}\right\}
$$

$k$ : sampling instant

- Fuzzification

The framework introduces Mamdani inference mechanism [22] to build the fuzzy rule. Forty nine rules with seven fuzzy sets were used in this controller namely, $\mathrm{Ng}$ (Negative grand); Nm (Negative medium); Ns ( Negative small); Zr (Zero); Ps (Positive small); Pm ( Positive medium); Pg (Positive grand),

- Fuzzy rules

Later, the fuzzificationphase of the inputs, a fuzzy inference machine is defined by the whole of IFTHEN rules to linkage the inputs to the output. Based on the exact and accurate knowledge of the VSWT comportment, these heuristic rules are expressed in fuzzy field which are summarized in Table 1. 
- Defuzzification

This phasebe made of converting the output linguistic variables to crispy values to attain the desired rotational speed of the PMSG.

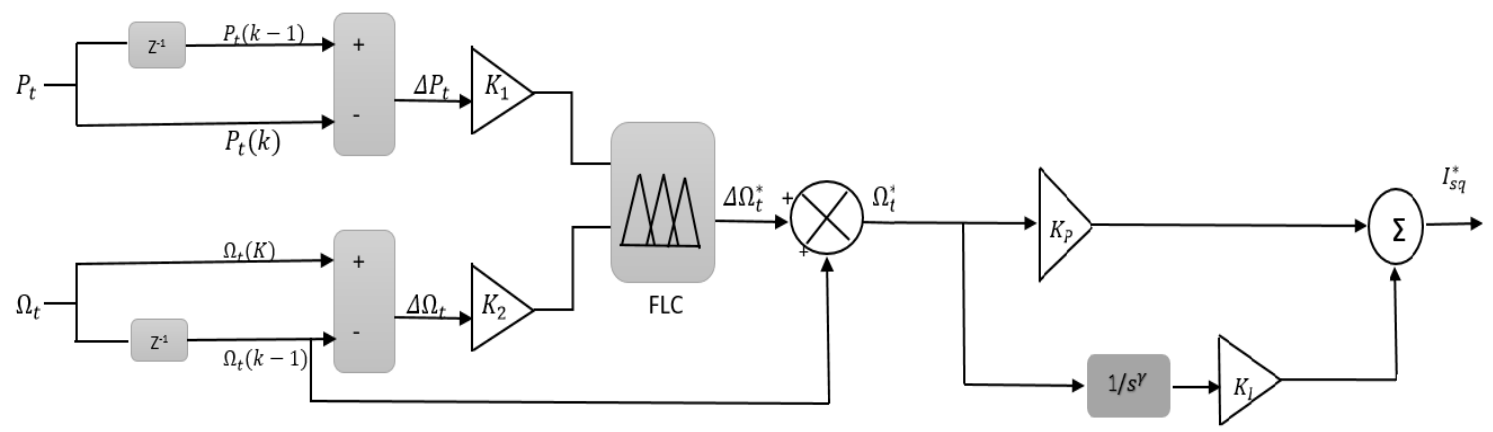

Figure 4. MPPT based on FFOPI strategy structure

Table 1. Rules of fuzzy logic controller

\begin{tabular}{ccccccccc}
\hline \multicolumn{1}{c}{$\Delta \Omega_{\text {tref }}$} & & \multicolumn{7}{c}{$\Delta \mathrm{P}_{\mathrm{t}}$} \\
& & $\mathrm{Ng}$ & $\mathrm{Nm}$ & $\mathrm{Ns}$ & $\mathrm{Zr}$ & $\mathrm{Ps}$ & $\mathrm{Pm}$ & $\mathrm{Pg}$ \\
\hline \multirow{6}{*}{$\Delta \Omega_{\mathrm{t}}$} & $\mathrm{Ng}$ & $\mathrm{Pg}$ & $\mathrm{Pm}$ & $\mathrm{Ps}$ & $\mathrm{Pm}$ & $\mathrm{Nm}$ & $\mathrm{Nm}$ & $\mathrm{Ng}$ \\
& $\mathrm{Nm}$ & $\mathrm{Pm}$ & $\mathrm{Ps}$ & $\mathrm{Ps}$ & $\mathrm{Ps}$ & $\mathrm{Ns}$ & $\mathrm{Nm}$ & $\mathrm{Ng}$ \\
& $\mathrm{Ns}$ & $\mathrm{Ps}$ & $\mathrm{Pm}$ & $\mathrm{Ps}$ & $\mathrm{Ps}$ & $\mathrm{Ns}$ & $\mathrm{Ns}$ & $\mathrm{Ng}$ \\
& $\mathrm{Zr}$ & $\mathrm{Zr}$ & $\mathrm{Zr}$ & $\mathrm{Zr}$ & $\mathrm{Zr}$ & $\mathrm{Zr}$ & $\mathrm{Ps}$ & $\mathrm{Pm}$ \\
& $\mathrm{Ps}$ & $\mathrm{Ns}$ & $\mathrm{Ns}$ & $\mathrm{Ns}$ & $\mathrm{Ps}$ & & & \\
& $\mathrm{Pm}$ & $\mathrm{Nm}$ & $\mathrm{Nm}$ & $\mathrm{Nm}$ & $\mathrm{Ps}$ & & $\mathrm{Pg}$ & \\
& $\mathrm{Pg}$ & $\mathrm{Ng}$ & $\mathrm{Nm}$ & $\mathrm{Ns}$ & $\mathrm{Pm}$ & & & \\
\hline
\end{tabular}

Fractional-order calculus (FOC) is one of the popular and emergent mathematics branches that deals with differentiation and integration of real or complex order [23-25]. Fractional-order mathematical phenomena are very useful to define and model real-time system more precisely than the conventional integer methods. The fractional-order differentiator can be represented by aoverall fundamental operator as a generalization of the differential and integral operators, which is defined as follows [25]:

$$
{ }_{a} D_{t}^{\gamma}= \begin{cases}\frac{d^{\gamma}}{d t^{\gamma}} & , \mathfrak{R}(\gamma)>0 \\ 1 & , \mathfrak{R}(\gamma)=0 \\ \int_{0}^{t}(d \tau)^{-\gamma} & , \mathfrak{R}(\gamma)<0\end{cases}
$$

One of the most generally used definitions in FOC is the Caputo definition [26]:

$$
{ }_{a} D_{t}^{-\gamma} f(t)=\frac{1}{\Gamma(n-\gamma)} \int_{a}^{t} \frac{f^{(n)}(\tau)}{f(t-\tau)^{\gamma-n+1}}
$$

where:

$$
\Gamma(\gamma)=\int_{0}^{\infty} e^{-\mu} u^{\gamma-1} d u, \mathfrak{R}(\gamma)>0
$$


is the Euler's Gamma function, $a$ and $t$ are the limits of the operation, and $\gamma$ is the integral fractional-order which can be a complex number. In this paper, $\gamma$ is assumed as a real number satisfying $0<\gamma<1$. Also, $a$ is taken as a null value and the following resolution is used: ${ }_{0} D_{t}^{-\gamma}=D_{t}^{-\gamma}$

Based on the Riemann-Liouville,in the time domain the fractional order FOPI controller transfer function can be rewritten as follows [27, 28]:

$$
u(t)=K_{p} e(t)+K_{i} \int_{0}^{t} \frac{(t-\tau)^{\gamma-1}}{\Gamma(\gamma)} e(\tau) d \tau
$$

In the fractional order FOPI controller, the weighted error is integrated instead of the error value. In this weighted integration, at time $\mathrm{t}$, the function: $\frac{(t-\tau)^{\gamma-1}}{\Gamma(\gamma)}$ plays the role of weight function for integrating the error history $(\tau), \tau \in[0, t][27]$.

In simulation and practices, the implementation of the fractional order term $\left(\frac{s}{\Omega_{t}}\right)^{\gamma}$ must be approximate by an integer transfer function, whereas a few methods have been established. Oustaloup's continuous approximation (OCA) is very used to approximate the fractional order $\left(\frac{s}{\Omega_{t}}\right)^{\gamma}$ to integer transfer function [29]. The parameters of the simulated system and the controllers used are respectively given by:

$$
K_{1}=0.0012, K_{2}=0.0019, \quad K_{I}=3.36, \quad K_{P}=4.86, \gamma=0,429
$$

with: $K_{1}$ and $K_{2}$ are the respective normalized scaling factors of the two inputs and output.

\section{RESULTS AND ANALYSIS}

The simulations results are made in the Simulink interface of Matlab. The parameters of the PMSG used in this paper are showed in Tables 2 and 3. Figure 5 displays the variation of the wind speed according to the time up to $\mathrm{t}=10 \mathrm{~s}$ between generated random values ranging from $\mathrm{v}=7.8 \mathrm{~m} / \mathrm{s}$ to $\mathrm{v}=14.15 \mathrm{~m} / \mathrm{s}$. Figures 6--8 present the system performances using PI, FOPI and FFOPI controllers. The Figures 6(a), 7(a), 8(a) demonstrate that FFOPI method has remained the highest average value of power coefficient. The Figures 6(b), 7(b), 8(b) were found the difference between the measured and referenced speed. Finally the Figures 6(c), 7(c), 8(c) were present the extracted power by the turbine that follow the desired trajectory $\mathrm{P}_{\mathrm{opt}}$ with different efficiency. From the simulations results and the analysis summarized in Table 4, it can be observed that the proposed controller FFOPI provides better performances to extract maximum power point for variable wind profile than FOPI and the PI controllers.

Table 2. Wind turbine parameter

\begin{tabular}{ll}
\hline Description of parameters & Values and units \\
\hline Air density & $\rho=1.225 \mathrm{~kg} . \mathrm{m}^{3}$ \\
Rotor radius & $R=2 \mathrm{~m}$ \\
The pitch angle & $\beta=0^{\circ}$ \\
Specific optimal speed & $\lambda_{\text {opt }}=8.1$ \\
Coefficient of maximum power & $C_{p \max }=0.48$ \\
\hline
\end{tabular}

Table 3. PMSG parameters

\begin{tabular}{ll}
\hline Description of parameters & Values and units \\
\hline Rated power & $P_{e}=10 \mathrm{KW}$ \\
Stator resistance & $R_{s}=0.00829 \Omega$ \\
Stator direct inductance & $L_{d}=0.174 \mathrm{mH}$ \\
Stator quadrature inductance & $L_{q}=0.174 \mathrm{mH}$ \\
Permanent magnet flux & $\Psi_{m}=0.071 \mathrm{wb}$ \\
Number of pole & $N_{p}=6$ \\
Inertia & $J_{t}=0.089 \mathrm{Kg} . \mathrm{m}^{2}$ \\
\hline
\end{tabular}




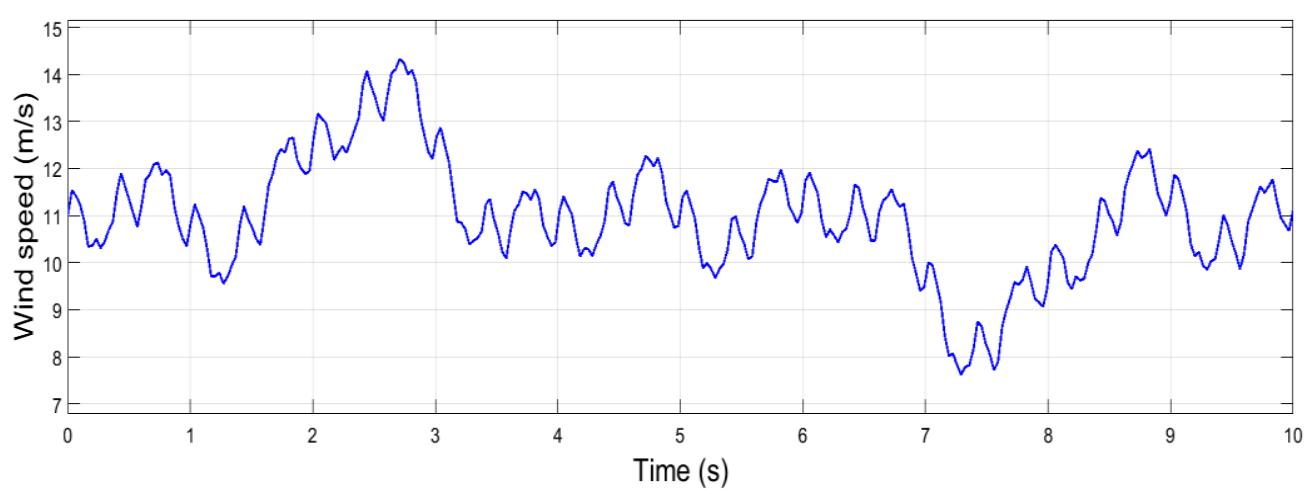

Figure 5. Wind profile

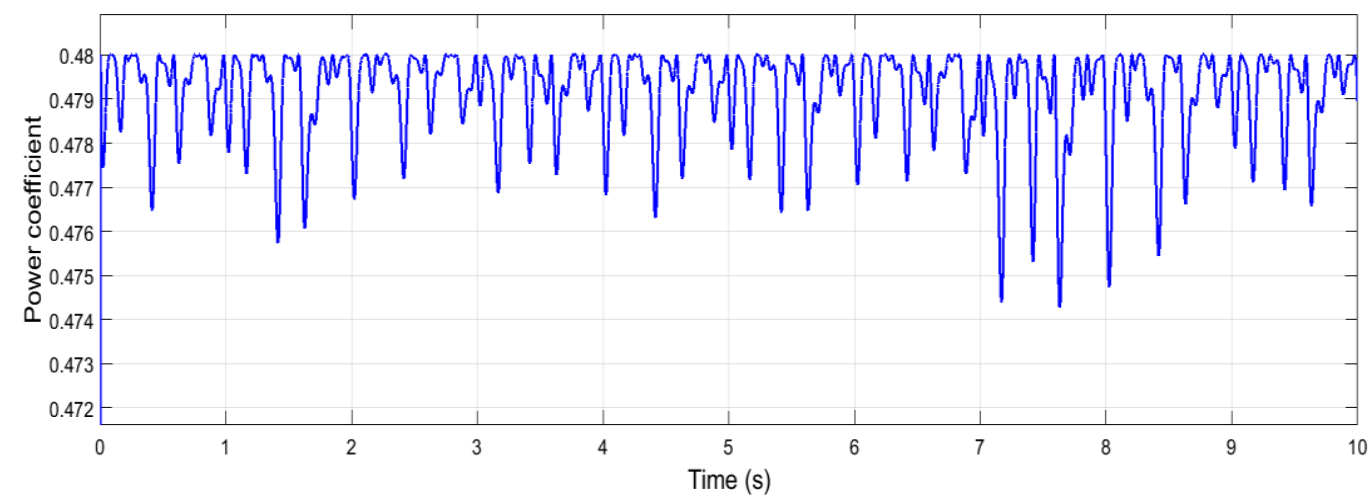

(a)

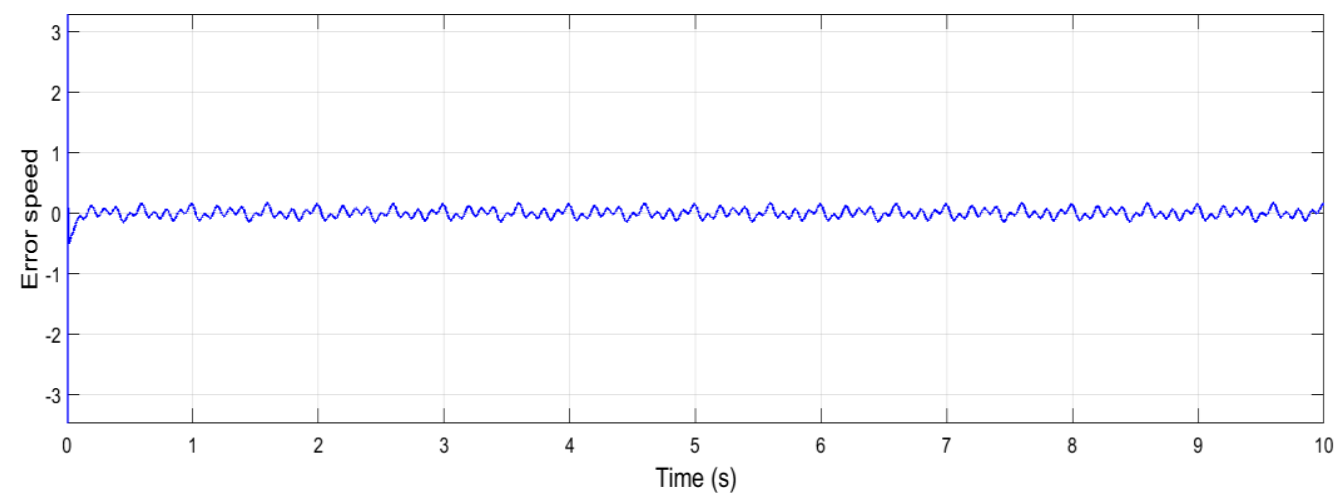

(b)

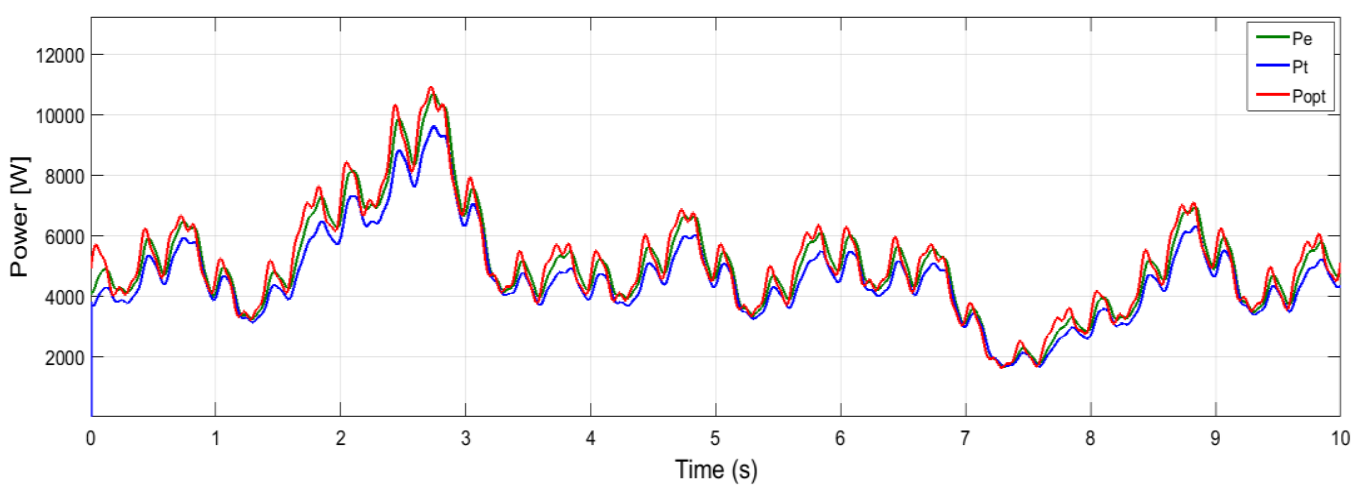

(c)

Figure 6. (a) The power coefficient (Cp), (b) Error speed, (c) Power, using PI controller 


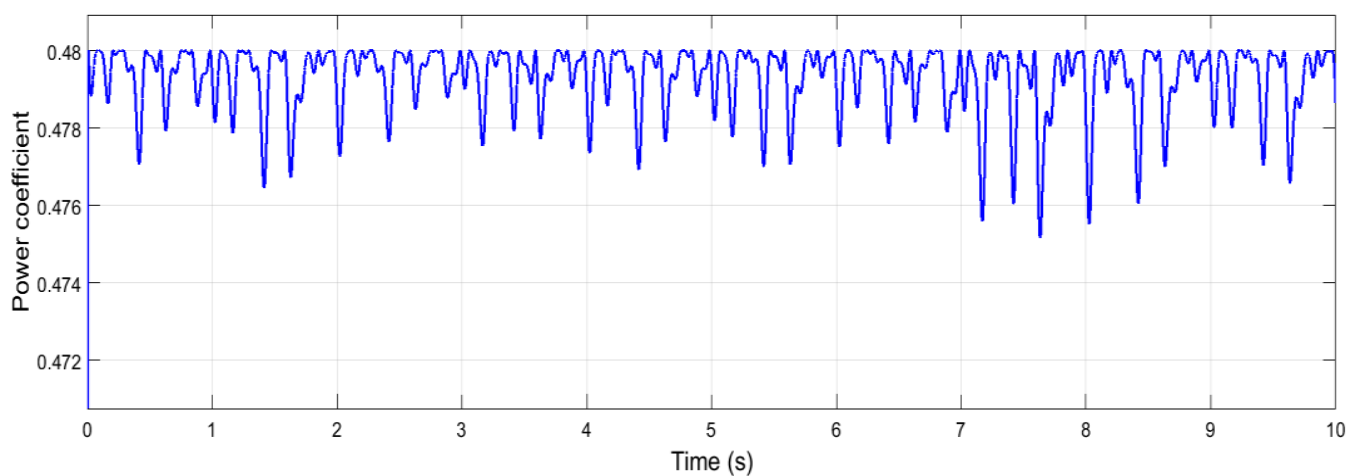

(a)

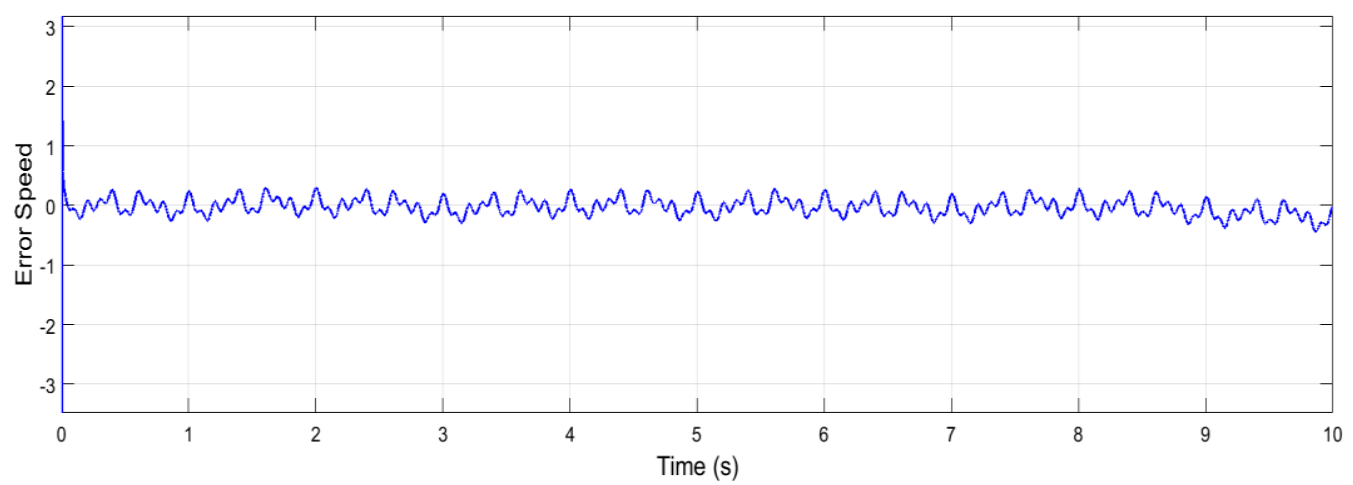

(b)

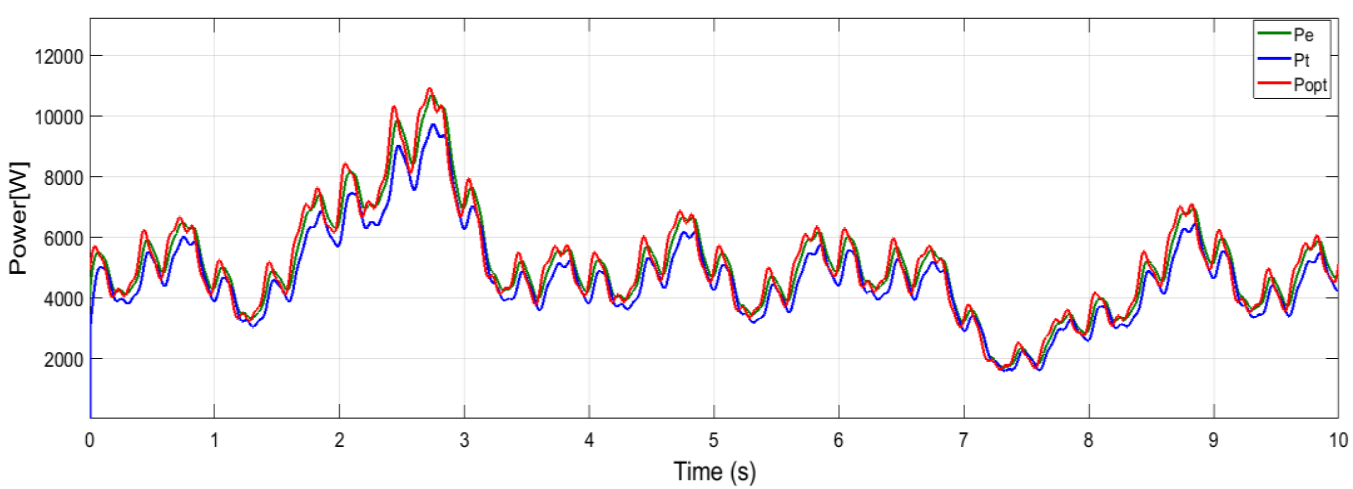

(c)

Figure 7. (a) The power coefficient (Cp), (b) Error speed, (c) Power, using FOPI controller

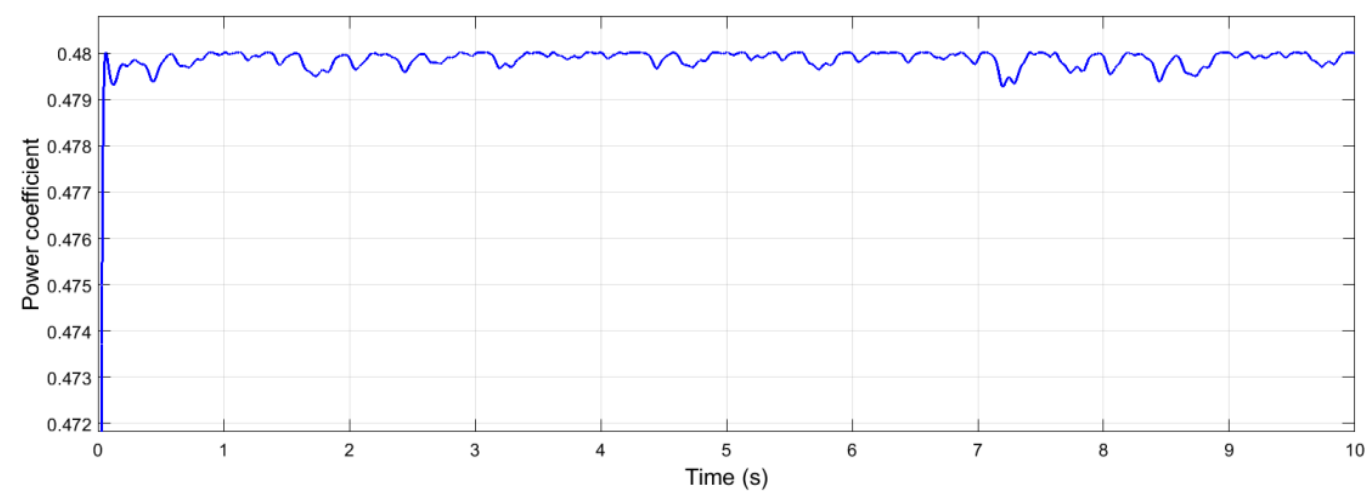

(a)

Figure 8. (a) The power coefficient (Cp) using FFOPI controller 


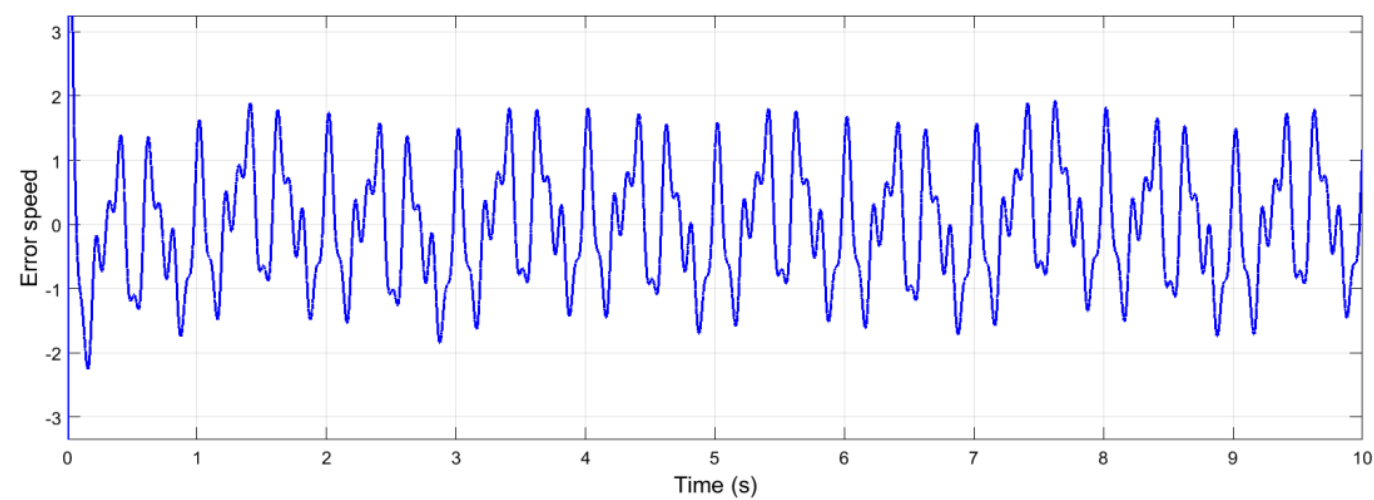

(b)

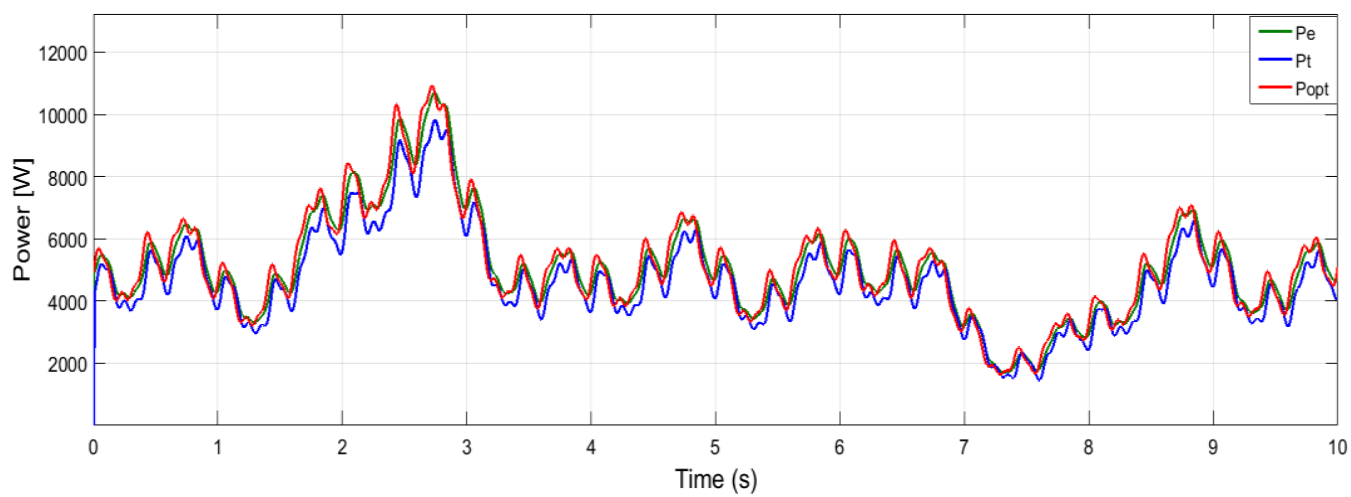

(c)

Figure 8. (b) Error speed, (c) Power, using FFOPI controller (Continue)

Table 4. Summary of performance of proposed methods

\begin{tabular}{cccccc}
\hline $\begin{array}{c}\text { MPPT } \\
\text { technique }\end{array}$ & $\begin{array}{c}\text { Average } \\
\text { power } \mathrm{P}_{\mathrm{t}}[\mathrm{kw}]\end{array}$ & $\begin{array}{c}\text { Power } \\
\text { coefficient }\end{array}$ & $\begin{array}{c}\text { Response } \\
\text { time }(\mathrm{s})\end{array}$ & $\begin{array}{c}\text { Efficiency } \\
\left(\mathrm{P}_{\mathrm{t}} / \mathrm{P}_{\mathrm{opt}}\right)\end{array}$ & $\begin{array}{c}\text { Efficiency } \\
\left(\mathrm{P}_{\mathrm{e}} / \mathrm{P}_{\mathrm{opt}}\right)\end{array}$ \\
\hline PI & 5.9598 & 0.4778 & 0.0964 & 0.9823 & 0.9384 \\
FOPI & 5.9613 & 0.4782 & 0.0764 & 0.9847 & 0.9327 \\
FFOPI & 5.9659 & 0.4797 & 0.0703 & 0.9865 & 0.9280 \\
\hline
\end{tabular}

\section{CONCLUSION}

Variable speed wind turbine systems havebeen getting widest attention among the various renewable energy systems, the use of an MPPT algorithm is indispensable for enhancing energy capture performance of VSWT. In this work, a FFOPI controller is designed to track maximum power point from PMSG integrated in variable speed wind turbine. The scheme performances are compared with those obtained with fractional order proportional integral and conventional PI controllers. The simulation results prove that FFOPI controller provides better performances than FOPI and PI controllers in rapports of robustness, efficiency and response time. The simulation has been done using Matlab/Simulink® platform.

\section{REFERENCES}

[1] Stiebler M., "Wind energy systems for electric power generation," Springer Science \& Business Media, 2008.

[2] Dadone A., and Dambrosio L., "Estimator based adaptive fuzzy logic control technique for a wind turbine generator system," Energy conversion and management, vol. 44, no. 1, pp. 135-153, 2003.

[3] Lubosny Z., "Wind turbine operation in electric power systems," Berlin:Springer, 2003.

[4] Balasundar C., Sudharshanan S., and Elakkiyavendan R., "Design of an Optimal Tip Speed Ratio Control MPPT Algorithm for Standalone WECS," International Journal for Research in Applied Science and Engineering Technology, vol. 3, no. 5, pp. 442-450, 2015.

[5] Jianhu Yan, H. Lin, Yi Feng, and Z. Q. Zhu., "Control of a grid-connected direct-drive wind energy conversion system,” Renewable Energy, vol. 66, pp. 371-380, 2014. 
[6] Guo Hong-che, Qiu Tian-yu, Jiang Jiu-chun., "Design of fuzzy controller for direct drive wind turbines," Journal of Shanghai Jiaotong University (Science), vol. 17, no. 2, pp. 209-214, 2012.

[7] Jahmeerbacus I. and Bhurtun C., "Fuzzy control of a variable-speed wind power generating system," Energize, 2008.

[8] Assareh, E., and Biglari M., "A novel approach to capture the maximum power from variable speed wind turbines using Pi controller, RBF neural network and GSA evolutionary algorithm," Renew Sustain Energy Rev, vol. 51, pp. 1023-1037, 2015.

[9] Roberto Cárdenas and Rubén Peña., "Sensorless vector control of induction machines for variable-speed wind energy applications," IEEE Trans On Energy Conversion, vol. 19, no. 1, pp. 196-205, 2004.

[10] Eftichios Koutroulis and Kostas Kalaitzakis, "Design of a maximum power tracking system for wind-energy conversion applications," IEEE Transactions on Industrial Electronics, vol. 53, no. 2, pp. 486-494, 2006.

[11] Sabzevari S., et al., "MPPT control of wind turbines by direct adaptive fuzzy-PI controller and using ANN-PSO wind speed estimator," Journal Of Renewable And Sustainable Energy, vol. 9, no. 1, 2017.

[12] Lei Y. et al., "Design of Robust adaptive neural switching controller for robotic manipulators with uncertainty and disturbances," Journal of Intelligent \& Robotic Systems, vol. 77, no. 3-4, pp. 571-581, 2015.

[13] Beddar A., et al., "Experimental enhancement of fuzzy fractional order PI+I controller of grid connected variable speed wind energy conversion system," Energy Conversion and Management, vol. 123, pp. 569-580, 2016.

[14] Mirecki A., Roboam X. and Richardeau F., "Architecture complexity and energy efficiency of small wind turbines," IEEE Transaction on Industrial Electronics, vol. 54, no. 1, pp. 660-670, 2007.

[15] Heier S., "Wind energy conversion systems. in grid integration of wind energy conversion systems," John Wiley \& Sons Ltd.: Chicester, UK, pp. 34-36, 1998.

[16] M. R. Muyeen, S. M. R. Takahashi and J. Tamura, "A design fuzzy logic controller for a permanent magnet wind generator to enhance the dynamic stability of wind farms," Applied Sciences, vol. 2, no. 4, pp. 780-800, 2012.

[17] Park, I. P., and Clarke I., "Inverse clarke transformations MSS software implementations user guide," Microsemi Corporation, 2013.

[18] Chen C-H, C-M, and Tu C-S., "Maximum power point tracking-based control algorithm for PMSG wind generation system without mechanical sensors," Energy Convers Manag, vol. 69, pp. 58-67, 2013.

[19] Narayana M., Putrus G. A., Jovanovic M., Leung P. S., and McDonald S., "Generic maximum power point tracking controller for small-scale wind turbines," Renewable Energy, vol. 44, pp. 72-79, 2012.

[20] Abdullah M. A., Yatim A. H. M., and Tan C. W., "A review of maximum power point tracking algorithm for wind energy systems," Renewable Sustainable Energy Rev., vol. 16, pp. 3220-3227, 2012.

[21] Jain B., Jain S., and Nema R. K., "Control strategies of grid interfaced wind energy conversion system: An overview," Renew Sustain Energy Rev., vol. 47, no. 983-996, 2015.

[22] Mamdani E. H., and Assilian S., "An experiment in linguistic synthesis with a fuzzy logic controller," International Journal of Human, Computer Studies, vol. 51, pp. 135-147, 1999.

[23] MillerandB K. S.and Ross, "An introduction to the fractional calculus and fractional differential equations," A Wiley-IntersciencePublication, JohnWiley \& Sons, New York, NY, USA, 1993.

[24] Chen Y.Q., Petr'a`s I., and Xue D. Y., "Fractional order control-a tutorial," Proceedings of the American Control Conference (ACC '09), pp. 1397-1411, 2009.

[25] Podlubny I., "Fractional differential equations, vol. 198 of mathematics in science and engineering," Academic Press, San Diego, 1999.

[26] Oustaloup A., Levron F., Mathieu B., and Nanot F. M., "Frequency-band complex non integer differentiator: characterization and synthesis," IEEE Transactions on Circuits andSystems I: Fundamental Theory and Applications, vol. 47, no. 1, pp. 25-39, 2000.

[27] Luersen M. A. and le Riche R., "Globalized nelder-mead method for engineering optimization," Computers and Structures, vol. 82, no. 23-26, pp. 2251-2260, 2004.

[28] Tavazoei M. S., "From traditional to fractional PI control," IEEE Industrial electronics magazine, vol. 6, no. 3, pp. 41-51, 2012.

[29] Shahab Ghasemi, Ahmad reza Tabesh, and Javad Askari-Marnani, "Application of fractional calculus theory to robust controller design for wind turbine generators," IEEE transactions on energy convers, vol. 29, no. 3, pp. 780-787, 2014.

\section{BIOGRAPHIES OF AUTHORS}

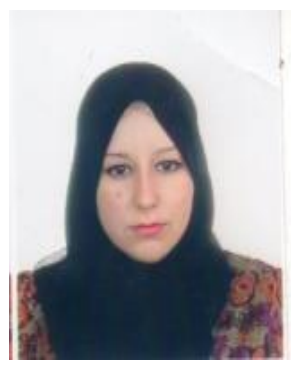

Meriem Otmane Rachedi was born on June 4, 1987 in Annaba Algeria. She recieved the diploma license in Automatic from University of Annaba in 2008, and recieved the diplomat Master in Industrial Automatic from University of annaba in 2010. Now she is $\mathrm{PhD}$ student with laboratory of Automation and signals Annaba (LASA), Algeria? Here research interests include Control systems, electric machines, and wind power. 

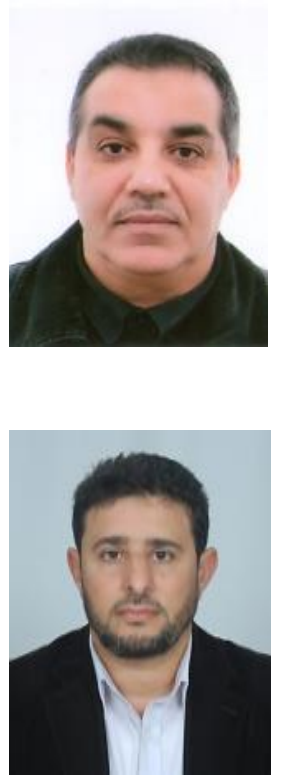

Mohammed Larbi Saidi was born in Annaba (Algeria), on March $29^{\text {th }}, 1966$. He graduated the Badji Mokhtar University, Faculty of Engineering in Annaba (Algeria), in 1990. $\mathrm{He}$ received the $\mathrm{PhD}$ degree in Automation from the Badji Mokhtar University of Annaba (Algeria), in 2006. He is Associate Professor at Electronics Department of Badji Mokhtar University, in Annaba (Algeria). His research interests concern: Control systems, electric machines, and wind power.

Fayçal Arbaoui was born on June $9^{\text {th }}, 1966$ in Annaba (Algeria). He graduated from the Badji Mokhtar university (BMU) in Annaba, and received the $\mathrm{PhD}$ degree in automatic control in 2006. He is teaching Automatic control since 1992 as an Associate Professor at Electronics Department of the BMU University. His research focuses on intelligent automatic control, fault diagnosis and fault tolerant control, especially in the fields of electric machines, wind power and irrigation 